\title{
The world of biomedical research
}

It is a truism that science is an international enterprise. After all, knowledge recognizes no geographic boundaries. Furthermore, by consensus the knowledge of science is shared around the world through a common language - English.

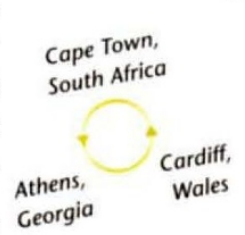

Camaraderie is enhanced by bonds forged at scientific meetings that take place in all corners of the globe, making researchers among the most well-traveled people in the world. But despite the rhetoric, it is only now that international collaboration, which was once an occasional occurrence for small, investigator-initiated research, is really the norm. A cursory review of the authorship of papers in just about any biomedical journal reveals the astonishing extent to which single studies are being conducted across state and national borders, across continents and oceans.

The May issues of Nature Medicine, Nature Genetics and Nature Structural Biology illustrate the point. Nearly half of the articles present collaborations involving more than one country. In some cases collaboration consists of little more than sharing materials: antibodies, viruses, peptides, or crystals, for instance. In other instances, particularly in studies of genetic pedigrees or experimental protocols for new therapies in diseases such as cancer, AIDS, or vascular disorders, collaboration depends upon data

gathered from large cohorts of patients at many institı Hyogo, tions. Research on Japan so-called emerging infections that are Tucson, often carried across na-

Baku, Azerbaijan

\section{tional boundaries by}

human hosts flying around the world for work or pleasure, demands international collaboration for obvious reasons.

Often the driving force is simply shared intellectual curiosity and compatible experimental taste. And, of course, the interdisciplinary nature of most cuttingedge research is a powerful incentive for people in different specialties to come together to solve a problem. These days, it is more than likely that these interdiscipli- nary teammates will not come from the same institution, or the same city, or even the same country. Biochemists need immunologists; hematologists need structural biologists; virologists need colleagues with experience in vaccine development. The ease of travel and the Internet, of course, facilitate interna-

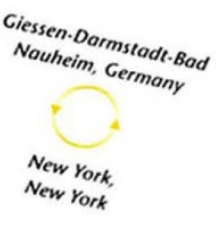
tional collaboration that would have once been almost impossible.

Thus, as the twentieth century draws to a close, the term "biomedical community" takes on new meaning, which is good for science and good for the patients whom science serves.

\section{More on death and dying}

The contentious issue of physician-assisted suicide, much debated but unresolved, took a new turn recently when two legally influential federal appeals courts in the United States ruled, for different reasons, that it is lawful for physicians to help patients die (see pages 616 and 617). The Ninth Circuit Court of Appeals, which has jurisdiction over western states, declared that a ban on physician-assisted suicide violates the Due Process provision of the 14 th amendment. The Second Circuit Court of Appeals took a different tack to the same end. In order to force people to live against their will, the State must demonstrate a "compelling interest" that overrides an individual's right to autonomy. There is no such compelling interest, said the Court, which covers New York, Connecticut, and Vermont.

Each ruling will be appealed to the U.S. Supreme Court. Already, it looks as if physician-assisted suicide will raise passionate argument akin to that surrounding abortion. The issue has already divided the medical community itself into two camps - those who hold that the preservation of life is a sacred trust versus those who believe that modern medicine's capacity to prolong dying needs to be moderated with compassion for the terminally ill or demented.

The subject of doctors helping people die has been one of the last to come into open public discussion. In fact, a recent study revealed that, even with a nurse trained as an advocate of conversation, a majority of physicians still failed to engage in straight talk about decisions at the end of life (Nature Med. 2,$129 ; 1996)$. As a result of the two recent judicial decisions, physicians who have never spoken up before are coming forward. For instance, a doctor in the small town of Bar Harbor, Maine, wrote to the local newspaper saying, "I am prepared and willing to assist anyone in this matter in any way I can." Channing Washburn, who has been a physician for 40 years, says outright that he can understand that people with total paralysis, Alzheimer's, or progressive wasting diseases might choose suicide. "A lot of people, as they get to an advanced age, hope their lives end in an easy and peaceful way. And I think they have a right to expect that," he says.

There are doctors like Channing Washburn living in silence all over the medical world. We can expect to hear from a lot of them now. It is time. They will add an important element to a debate that is, at once, about philosophy, morality, and the reality of illness and death.

- Barbara J. Culliton 